Pablo Ortúzar, El poder del poder. Repensar la autoridad en tiempos de crisis (Santiago: Tajamar Ediciones, 2016).

RESEÑA

\title{
DEL ORDEN SAGRADO A LA OPCIÓN PREFERENCIAL POR LOS NIÑOS
}

\author{
Manfred Svensson
}

Universidad de los Andes

I 1 argumento se desparrama hacia mil partes", 1 nota de Pablo Ortúzar con la que explica las dificultades a la hora de poner cierre a El poder del poder. El lector puede haber tenido esa sensación mucho antes de llegar a la conclusión. Pues mientras el título de esta obra genera la expectativa de una concentrada reflexión sobre una dimensión de la vida en común — la del poder-, la obra se extiende, en realidad, desde la reflexión básica sobre la sociabilidad humana hasta la cuestión de la opción preferencial por los niños. Si esta expresión se ha vuelto hoy parte de nuestro discurso político, en este libro no es una fórmula cualquiera, sino un intento por dar concreción a la pregunta por las víctimas del orden social. Entre estos asuntos aparecen la discusión sobre el carácter mimético de la cultura humana, los problemas de la representación y la peculiar mirada que recae sobre las élites en periodos de crisis. La bisagra que une estos tópicos no es una convencional clasificación de los modos de dividir el poder político y el poder social. Se trata de inquirir sobre el poder y su división, pero en particular pre-

Manfred Svensson. Doctor en filosofía por la Universidad de Munich, Alemania. Director del Instituto de Filosofía de la Universidad de los Andes. Email: msvensson@ uandes.cl.

${ }^{1}$ Pablo Ortúzar, El poder del poder. Repensar la autoridad en tiempos de crisis (Santiago: Tajamar Ediciones, 2016), 209. El libro se citará, en adelante, tan sólo con su número de página entre paréntesis. 
guntar por el modo de relacionarnos con las víctimas que todo orden social produce. Dichas preguntas remiten, a su vez, a una reflexión sobre la naturaleza misma del hombre y los modos en que lo sacro se vincula con el orden.

Muchas de las preguntas así tocadas se cruzan con la inquietud por la subsidiariedad, que Ortúzar ha contribuido a revitalizar en el debate nacional durante los últimos años (véase su edición del libro Subsidiariedad: más allá del Estado y el mercado ${ }^{2}$ y su traducción de La gran sociedad, de Jesse Norman). ${ }^{3}$ Pero aquí, como ya lo sugiere nuestra síntesis, dichas preocupaciones se encuentran insertas en las preguntas más fundacionales que el autor se plantea como antropólogo. En concreto, en este libro desempeña un papel fundamental la obra de René Girard y su idea de que el surgimiento de lo sagrado y del orden social se vinculan con la violencia sacrificial ejercida contra figuras luego mitificadas. El "poder del poder" radica en la legitimidad adquirida de dicha fuente. La inquietud que atraviesa el libro desde diversos ángulos es si acaso el poder puede fundarse de otro modo.

Dado el trasfondo en Girard, se encuentra de modo recurrente en el libro la tesis según la cual la humanidad es hija de lo religioso, con el orden cultural fundamentado en el orden de lo sagrado. En nuestra discusión política y cultural, tal tesis puede encontrarse con objeciones provenientes desde dos polos: Desde un lado se podría elogiar que el fundamento sacro del orden social sea recogido, criticando, eso sí, la aparente reducción que se hace de dicho carácter sacro al fenómeno de la violencia sacrificial. Desde otro lado, se podría sostener que la perspectiva adoptada en la obra permite en realidad explicar el funcionamiento de sociedades premodernas, pero que en la nuestra, desvestida de todo encantamiento, resulta una explicación superflua. Las dos objeciones parecen pertinentes, y considerarlas nos puede dar una adecuada vía de acceso a lo que el autor se propone en este libro.

Si hay un fundamento sagrado del orden social, dicho fundamento puede efectivamente exhibir muchos rostros (misterio, don, mediación y un largo etcétera). Cabría entonces objetar que aquí se privilegia de

${ }^{2}$ Pablo Ortúzar, editor, y Santiago Ortúzar, coordinador, Subsidiariedad. Más allá del Estado y el mercado (Santiago: Instituto de Estudios de la Sociedad, 2015).

${ }^{3}$ Jesse Norman, La gran sociedad. Anatomía de la nueva política (Santiago: Instituto de Estudios de la Sociedad y Fundación Cientochenta, 2014). 
modo desmedido una de esas dimensiones, la del sacrificio. Pero parece pertinente responder a esta potencial objeción recordando el foco de la obra: no se trata de una exploración de los fundamentos sagrados de un orden social, sino de una exploración de una dimensión de dicho orden — la del poder-; es por su utilidad para iluminar éste que es introducida toda la teoría de Girard sobre las víctimas sacrificadas para frenar el conflicto y luego sacralizadas en relatos sobre el origen de la comunidad. Si la posición de Girard es plausible, el característico intento moderno por alcanzar la paz mediante la simple reducción de la influencia religiosa en el espacio público parece ocioso. Según lo explica la sucinta fórmula de Ortúzar, "no es lo sagrado lo que produce la violencia: es la violencia humana la que, a veces, produce lo sagrado" (45). Es bajo este prisma, insisto, que el trasfondo sagrado del orden social es abordado en el libro, y no parece pertinente extrapolar desde ahí respecto de otras relaciones de dicho orden con la religión: las tesis del libro podrían, me parece, leerse de un modo que se las considere abiertas a más relaciones de ese tipo, pero también admitirían una lectura más secularizadora.

En cualquier caso, planteadas así las cosas, la solución moderna a estos asuntos deja de tener la forma que presentamos en la segunda objeción: efectivamente, hay una novedad moderna, pero ésta consiste ante todo en la complejidad de los modos de representación, que van separando el orden social del plano de lo sagrado. Eso puede leerse como un lado de la secularización. Pero no hay que olvidar que la nacionalización de las iglesias o los intentos por sacralizar el Estado son parte de la misma trama moderna. Y en dicha historia sigue habiendo víctimas. Éstas no siempre son sacralizadas de los modos que Girard describe como típicos de las sociedades premodernas, pero también nosotros oscilamos entre ver a las víctimas como dioses o bestias, castigándolas o temiéndolas en periodos de normalidad, volviendo la mirada esperanzada sobre ellas en momentos de crisis. Culpar y sacrificar a las víctimas o poner las esperanzas de renovación en ellas son fenómenos que hundirían sus raíces en un mismo terreno (60). Quien esté atento al lugar que ocupa el victimismo en una infinidad de problemas actuales — véase, por ejemplo, The Rise of Victimhood Culture, de Manning y Campbell— no tendrá dificultad para comprender la manera en que desde este género de reflexión Ortúzar logra transitar al análisis político y cultural. 
En efecto, este marco de interpretación es usado por Ortúzar para descender a un análisis bastante pormenorizado de la cultura contemporánea. Así, por ejemplo, se estudia la introyección del sacrificio como una de las transformaciones modernas del mismo (un tópico que en nuestro medio también fue central para Pedro Morandé). La idea de que cada uno se esfuerza y se sacrifica por los otros es descrita como una vía que traspasa en apariencia el poder a los consumidores, pero que lo difumina de modo tal que hace difícil volver el mecanismo sacrificial contra los que ejercen el poder (63). Entroncando aquí con el análisis de Byung-Chul Han en La sociedad del cansancio, Ortúzar se muestra atento a los riesgos de esta realización mediante el autosacrificio, que bien puede terminar en un simple narcisismo de sujetos cansados e incapaces de relación (157). El libro desciende también, de modo cauteloso pero agudo, a la política nacional, haciendo notar cómo este trasfondo ilumina los problemas de un Sebastián Piñera sin nada en nombre de lo cual gobernar, así como los problemas de una Michelle Bachelet a la que le tocó guiar a una izquierda que por primera vez no gobernaba en nombre de ninguna víctima (112-115).

Pero en lo que a discusión política se refiere, sin duda la dimensión más vigorosa del libro es el doble acento puesto en la subsidiariedad y el pluralismo. El primero de estos puntos cuenta con un propio capítulo que podría haber sido más extenso. Sus publicaciones previas sobre el punto pueden haberlo llevado aquí al autor a una innecesaria parquedad; aunque el argumento del libro no se ve afectado por ésta, es evidente que algo padece la forma. Pero de subsidiariedad se puede hablar no sólo en el sentido cuidadosamente delimitado que se usa en dicho capítulo, sino que también como término que nos recuerda la dimensión comunitaria de la existencia humana. En este sentido, es un tópico que se encuentra presente mucho más allá del capítulo específico dedicado a la subsidiariedad. Hay una conciencia aguda, en otras palabras, de que no vivimos "en sociedad", sino en sociedades, en un complejo conjunto de agrupaciones naturales y voluntarias que se entrecruzan (73-107). Esta distribución del poder que una sociedad civil fuerte trae consigo es vista como una contribución fundamental para contrarrestar la violencia sacrificial (95).

Una política que deje atrás la violencia sacrificial parece además exigir su propio modo de legitimidad, uno que sea altamente participa- 
tivo. Eso implica no sólo cierto modo de organización, preocupado por la pluralidad del orden social, sino también una cierta disposición. Ortúzar nos habla de ella hacia el final, donde aborda la cuestión de cuánta distancia se requiere respecto de la propia posición para poder respetar la del otro. Acertadamente, me parece, el autor cuestiona aquí aquellos proyectos que proponen ese tipo de fuerte distanciamiento como fundamento para la sociedad plural. Los hombres no logran relativizar a tal extremo la propia forma de existencia, y constituye por tanto un riesgoso estrechamiento de nuestras posibilidades el que atemos el pluralismo a tal distancia.

La pregunta fundamental, en cualquier caso, es si acaso para el hombre es posible vivir fuera de mitos que oculten una violencia arbitraria, mitos que lo ponen a él y a su grupo de preferencia en una posición privilegiada (136). Ortúzar no se hace aquí ilusiones: ve muy bien que no hay orden social sin víctimas. Por lo mismo, la meta propuesta no es la de una sociedad sin víctimas, sino una consciente de las mismas. En síntesis, el ideal al que apunta el libro es el de "una sociedad cuyas organizaciones se encuentran imbricadas en una tensión virtuosa, que no construye su identidad sobre la negación de la identidad de otros, que construye mecanismos para poder auto observarse (y observar así a sus propias víctimas) y que no legitima la violencia ni el resentimiento de unos grupos sociales contra otros dentro de sí" (126). Se trata de un género de reflexión muy singular en un país cuya reflexión pública está dominada por disciplinas menos atentas a estas dimensiones de lo humano. Si en alguna dirección peca este libro, es en el intento por abordar de modo simultáneo tantos problemas de envergadura. En cualquier caso, el lector notará con facilidad que no es extravagancia lo que está en cuestión: el autor nos guía de modo hábil desde la oscura reflexión sobre el sacrificio a discusiones muy aterrizadas sobre la opción preferencial por los débiles y sobre el desafío de la justicia intergeneracional. Lo anima cierta distancia crítica con el ideal moderno de progreso; pero en lugar de un simple desencantamiento respecto del mismo, nos mueve a una visión humilde del progreso, a una búsqueda de uno que reconozca a sus víctimas y que reconozca que no controla todas las variables. EP 